Fool's Gold: Selected Modjaji Short Stories.

Arja Salafranca, ed.

Cape Town: Modjadji Books, 2019. 209 pp.

ISBN 9781928215844.

In the foreword of Fool's Gold, the editor, Arja Salafranca writes that this short story collection "celebrates both the form of the short story and over a decade of publishing short stories" (7) by the South African independent women's publishing house, Modjaji Books. The book achieves this intention by providing the reader with varied stories, writing styles and stunningly gripping themes. The collection boasts of a variety of creative writers who write compelling stories, some of which have won local and international awards. The editor lastly makes the remark that the form of the short story has the potential to "hold up a mirror to our lives and the place we live in" (11). The reader sees this in the ways the various stories reflect and capture every-day life through different narrative 
strategies. The stories in this collection have the capacity to stay with the reader long after the initial reading has taken place.

Featuring seventeen stories that range from realist fiction to magic realism, Fool's Gold elicits a myriad of emotions from the reader. "Prayers", a story by Makhosazana Xaba which co-won the SALA Nadine Gordimer Short Story Award in 2014, evocatively comments on the horrific ramifications of AIDS on children who are orphaned by the disease. The story is narrated by Refilwe, a young, orphaned girl aged 13, who is taking care of her younger sister in the village of Bhekilanga in Limpopo. The story is narrated as a letter to an anonymous "you" at the request of Refilwe's teacher, Mistress Maluleke. Refilwe writes this letter as a way of seeking some financial relief and support. It is also a way of "consolidating all [her] prayers" (142) and to give a "full picture of [their precarious] lives" (143). Xaba points out the discrepancies of the current South African government in ensuring the health and safety of AIDS orphans by focusing on children and their experiences. The theme of childheaded households and the resilience of children is skilfully weaved into the narrative through Refilwe's naïve and honest observations of her society and environment. Refilwe engulfs the reader in the poverty her family faces by recounting her family's day-to-day routine as well as larger communal activities that they engage in. Refilwe's experiences awaken the reader to the prejudices of her community towards those living with HIV/AIDS and the blind eye that communities turn to this pertinent issue. As Refilwe reveals her predicament, as well as that of many others like her, it becomes clear that "[their] very own existence is parsimony" (133).

Meg Vandermerwe's "The Red Earth" is thematically linked to Xaba's "Prayers". It shifts the focus from the children orphaned by AIDS to the parents who die and leave their children behind. The narrator in "The Red Earth" is a mother on her hospital deathbed. As she recalls and remembers the past, observes the present and shares fears of the future, she laments that "soon soon, a country of orphans, soon soon" (33). Her situation is implicitly compared to that of orphaned children, as she too feels isolated and orphaned on the hospital bed where doctors speak and write about her and do not talk to her. She bemoans her isolation: "I am an orphan, understand. Apart from everything, everyone" (33).

In addition to being informative and entertaining, each story possesses a variety of rhythmic styles and beautiful imagery. Kubuitsele's "In the Spirit of
McPhineas Lata" is a delightful read that centers on the sexual expertise of the protagonist, McPhineas. The story begins with McPhineas' death. We are told how he has been an envy to the men, as well as a celebrated figure among the married women of Nokanyana village. In his lifetime he had made it his duty to sexually appease willing women in the village. Many called him "talented" while others argued that he "read books" (61) to acquire such prowess. Humorously, he dies "in the act of his more acrobatic performances" (61) leaving the concerned women grieving and spending their days lying on top of his grave. Similarly, in "Heaven (or something like it)" by Sarah Lotz, Adele spiritually returns to her old life and moves back into her flat where she watches TV 24/7. The tenants renting the flat after Adele's death are shocked to feel a "chill" in the flat indicating Adele's presence. None of the tenants stay long, until Carmen moves in. Surprisingly, Adele and Carmen enjoy similar shows and they become friends. They spend their free time watching fashion and reality shows. "[T]his was heaven after all" (105), for both women to find rare friendship somewhere between life and the afterlife.

Several stories allude to the (dis)continuities of human migration and movement. This theme has become popular in the South African literary landscape, especially with writers exploring the frequent outbreaks of xenophobic attacks. In "Stain like a Map", Jayne Bauling focuses on a couple's journey from Mozambique to South Africa. The story uses the metaphor of a mattress as a map or a trajectory that the couple's life has taken over space and time. The stains on the mattress are symbolic of the history of the couple. Not only is the mattress used for sleeping, but also for giving birth to their child and another child of a friend. They carry this mattress with them en route to South Africa by foot and through their displacements in South Africa. As the narrator observes, the stains which look like a map are "of those who had walked into South Africa" (56). In "Vivous Cycle", Reneilwe Malatji explores the issue of absent fathers. Although this is the overarching theme of the story, the concept of home in relation to migration is weaved intelligently into the story. At the start of the story we meet Adichie, a Nigerian academic working and living in South Africa. He outwardly condemns absent fathers by comparing the manifestations of this social phenomenon in Nigeria and South Africa. He tells us "most men here abandon their children. In Nigeria that never happens" (121). Furthermore, "a bird does better than most South African black men” (121). Through these comparisons, Adichie expresses the common duality of identity and 
culture that is shared by most migrants; the experience of being neither nor there.

The stories in this book have heavy themes highlighting a variety of people's life experiences. The many voices of characters in these stories reflect the diversity of people's stories as well as the diversity of the short story form.

\section{Nonki Motahane}

mnonkiy@yahoo.com; MotahaneNS@ufs.ac.za

University of the Free State

Qwaqwa, South Africa

ORCID: https://orcid.org/0000-0001-5858-4203

DOI: https://doi.org/10.17159/tl.v58i1.9128 